\title{
Research on the Application of Task-driven Teaching Method in Accounting Teaching
}

\author{
Man Le \\ Guizhou Light Industry Technical College, Guizhou, Guiyang 550025, China
}

Keywords: task-driven teaching method; accounting teaching; application research

\begin{abstract}
The accounting teaching in the new era is different from the previous teaching methods. For students majoring in accounting, to master the mastery of accounting, in addition to knowledge, it is necessary to improve the level of operation through practice. Only in this way can the accounting be well developed. The characteristics and development history of the task-driven approach are briefly summarized, and its application in accounting teaching is analyzed. It is hoped that this approach will promote the teaching of accounting disciplines.
\end{abstract}

\section{Introduction}

Task-driven teaching method is a brand-new teaching method. It uses task as the main line to drive students to learn, and combines teachers' guidance to enhance the learning interest. Compared with traditional teaching methods, the task-driven approach not only focuses on the ability of students to learn independently, but also emphasizes the process of cooperative learning. Therefore, students' learning effects will be better.

\section{About Task-driven Method.}

\subsection{The advantages of the task-driven approach.}

Teachers must use the task-driven approach to grasp the content of the teaching materials as a whole. With the joint efforts of teachers and students, they use a variety of teaching resources to identify problems and solve problems, and subtlety complete the teaching goals. This learning method has changed the intrinsic indoctrination style of knowledge, making it easier for teachers to teach, student learning to be more efficient, allowing students to participate in positiveness more proactively, and students' ability to solve problems on their own will also be improved, thereby experiencing a strong sense of satisfaction. The mind is more mature and cultivates the courage to explore. In the process of learning, teachers play a role in controlling the overall situation. Through the construction of the situation and the teaching of learning methods, the students are in the main position of the classroom. With the cooperation of teachers and students, the learning ability and 
cooperation ability of the students are enhanced [1].

\subsection{The development process of the task-driven approach}

In recent years, the task-driven approach has been widely respected in the field of teaching. This method is also constantly improving. In 1996, Jane Williams put forward an early model in the "task-driven learning framework". He believed that task-driven teaching should include three factors: pre-task activity, activity cycle and language. Afterwards, Hong Kong's education department pointed out that driving education should include five aspects: a clear teaching goal; creating a teaching situation; a learner's thinking model and behavioral norms; a task-oriented role of the task activity; The development of task-driven law has also been widely used in teaching in China, but the research direction and operation process of each scholar is not the same. In 2001, scholar Ai Fengping divided task-driven teaching into five processes, including the drive of problems and motivations, discussion of problems between teachers and students, the completion of tasks and the subsequent evaluation of effects, and finally summarized. Only a year later, $\mathrm{Wu}$ Wenzhuang believed that task-driven teaching should be refined into the following stages of learning: after full consideration, setting up learning tasks; creating teaching situations, clarifying teaching objectives; and organizing students to discuss and solve problems. In 2004, Xu Mingcheng also put forward the general flow of the task-driven model. Although these methods are slightly different in detail, the overall thinking is consistent and can be summarized as follows: First of all, students' theme status is clearly defined and then they are developed. The specific teaching objectives, combined with the task situation, will finally complete the learning task through cooperation. Teaching also incorporates the task-driven approach and has achieved very good results [2].

\section{The practical application of task-driven method in accounting teaching.}

\subsection{Integrate Accounting Teaching Contents to Simulate Accounting Work Situations}

In order to integrate the task-driven teaching method in the study of accounting, teachers must integrate knowledge that students need to learn and reorganize into many learning sections. When integrating accounting content, it is necessary to break the structure of past teaching materials, and try to converge with accounting practice content and abide by the relevant procedures of accounting operations. If there is transaction content on the original vouchers, it is necessary to make good accounting entries, and then register the account books in conjunction with the debit/credit bookkeeping method. Then balance the transaction amount with trial balance, and finally edit the accounting statements. Follow this procedure to break through the operations. In this way, the transaction records can be reflected and the accounting books can be installed. With the binding of a book, the students can firmly grasp the basics of accounting. From a construction task-driven perspective, a vivid learning situation will stimulate students to make better associations, allow students to deepen their memories of the original knowledge, and be more understandable when they are exposed to new knowledge, and the various task areas of accounting are connected. They are all very strong. When teachers create a task-driven program, they must do a good job of linking and arranging all aspects. Specific accounting work situations can be set in such a way that, on a large background, graduates of the accounting profession go to an auto parts manufacturer for internships, use industrial accounting work-flows as clues, and perform tasks according to the positions of the finance minister or finance director. The work was carried out with the entire staff of the finance department as a cooperation team. The knowledge of the church and the teaching objectives to be achieved were hidden in various sections. Then the task-driven method was implemented for 
different sections and practical work was carried out [3]. In order to achieve the desired effect, the teacher should allow the student to enter the working state at the beginning of the first class and use himself as an intern in the accounting position. The task to be accomplished is to strengthen and other tasks under the head of the accounting department or the head of the accounting department. Accounting staff positions and cooperation work together to complete the accounting work. At the same time, teachers should send teaching materials to students so that they can understand the economic business of this auto parts company and understand what the main business and other businesses are. At the same time, teachers must also establish blank accounting documents. And accounting books, so that students can through the financial software for entry and entry preparation, the post division of the students, to complete their respective tasks. In this way, the students will realize the working atmosphere in the real scene, and the interest in learning will grow stronger and grow faster. In the following sessions, teachers should make reasonable arrangements for different situations [4].

\subsection{To build and refine learning tasks}

Teachers should make detailed knowledge based on the characteristics of accounting disciplines and the students' knowledge of accounting theory and operation skills, combined with the work of industrial accounting, and reconstruct the accounting work flow according to the students' acceptance ability. The knowledge points are implanted into the work. In other words, it is the integration process of knowledge, which classifies accounting knowledge as an overall task and then gradually decomposes it into many small tasks. Each small task is related to knowledge and related to the content of the work. In the specific operation, the teacher should first arrange the task content, and explain the details, and the students should pay attention to the problem. When assigning tasks to each student, the teacher should let the students understand that the tasks that follow are related to the vital interests of the company and the employees. They must correct their attitudes, work hard, and cultivate a high sense of responsibility among the students, thus taking the professional ethics in the classroom. Students are put into practice.

\subsection{Autonomous learning and teamwork}

Autonomous learning is very important for the study of any subject. This link is an important prerequisite for students to complete their tasks. In the arrangement of accounting tasks, students should collect relevant data according to the teachers' requirements and the accounting knowledge they have learned, analyze and judge the content of the materials, and realize the knowledge reserve for the solution. Students can go to the reading room to find reference materials, and they can also search the Internet. Through the use of ideas and methods, they can gain experience and complete tasks. In the process of self-directed learning, students cannot always rely on the strength of teachers. They must seek assistance from teachers when necessary, mainly on clues. For example, after the entry is completed, the accounting statements need to be prepared. The teacher can allow students to download some previous company annual reports on the Internet. There are relevant data available, and students can grasp knowledge points to make the data more detailed and reliable. In addition, the individual differences of students are not the same, so teachers should give more help to students with poor ability, timely and effective guidance, improve student confidence in learning, training content learning ability, data collection capabilities. Autonomous learning not only accumulates material for group learning, but also lays the foundation for later learning and completion of tasks. Collaborative learning must be realized in the form of a group. Each member can be regarded as a specific employee in the accounting department. According to the post, he can be set up as an accountant, materials accountant, sales accountant, cost accountant, and cashier, and the post rotation system should be 
implemented. Teachers must ensure that the quality of learning needs to pay attention to the following three points: First, a reasonable allocation of collaborative teams. The assignment of the group is related to the final learning effect, because the students all hope that the team with better overall strength can be stronger and stronger; otherwise, the group with the larger difference will have too much difference because of the difference in the strength of each classmate. Difficulties, so teachers must grasp the "degree" so that there is a difference within each group, and the difference is not, and the strength of other groups is more close, so that it is conducive to the supervision of teachers, work well. Second, choose the team leader. The captain should have certain leadership skills, coordinate the work of the team, and be the leader in helping team members grow together. When the team leader's tasks are successfully carried out, the captain's own ability will rise to a good level, so it can be based on the situation of the team. Replace the captain so that the level of each member has improved. Third, pay attention to fostering collaboration and communication skills. The team members jointly analyze and exchange opinions on accounting issues, which will make their insights broader, and absorb other people's ideas will improve their own deficiencies, such as entry imbalances in entries, differences in the use of materials and turnover materials in transit. Such as, is conducive to training students' accounting literacy [5].

\subsection{Complete tasks through the resolution of problems}

Solving problems is the intermediate link of the task-driven approach. It plays a role in initiating and evaluating activities in the early stage, embodies the students' comprehensive knowledge level, and is also the process of the formation of innovation consciousness. For students, finding problems in specific situations is not an easy task. When accounting for the economic business of a company, sometimes the goal is not clear. For example, the cashier's notes are insufficient to support the data, not to mention the situation. The per-judgment, therefore, teachers should allow students to identify what issues must be resolved, allow students to combine the meaning of accounting entries and work conditions, and use the information collected on the Internet to integrate and make correct trials to solve problem. In this process, teachers must supervise the student's operation situation, find problems to let students know the solution, and get students closer and closer to their own goals. Moreover, with the successful completion of accounting tasks in various positions, teachers should give a positive eye to the students' enthusiasm for learning more intense and realize the sense of accomplishment of task completion [6].

\subsection{Use the evaluation system to summarize the tasks}

The evaluation of learning effectiveness is the final link, and its role is reflected in the test of the effectiveness of teaching. Of course, scoring based solely on the assessment of results is incomplete and unscientific. From the perspective of consideration, assessment assessment should be more comprehensive, first of all requiring students to have a good professional quality, that is accounting professional ethics. Secondly, in the accounting operation process, we must ensure the accuracy of the input, the standardization of the links, the spirit of assiduous study, and the spirit of solidarity and cooperation. Only by combining these factors can the assessment be more persuasive. At the same time, for different students, teachers must not only pay attention to the mastery of knowledge, but also to see the degree of change in each student, to achieve a "people-oriented" teaching philosophy, so teachers should observe the status of students, and discover what The reasons constrain the progress of the students. Of course, in addition to the evaluation of the students and the forms of mutual evaluation among the students, the examination results can also be innovative. For example, the teachers can set a period of one month to allow students to work on the basis of accounting. Under the requirements of the Work Regulations, the preparation of separate entries, the balance of loans, the 
accounting books for the month, and the formation of the current month's accounting statements. In addition, on the evaluation of the results, teachers should also observe the students' help to other people and other factors [7].

\section{Conclusion}

The task-driven teaching method plays an important role in accounting teaching. It can achieve the improvement of student accounting literacy and the improvement of teacher's teaching level. This article briefly summarizes the application of task-driven method in accounting teaching and hopes to study student accounting.

\section{References}

[1] Liao Yiping, et al. Analysis of the Specific Application of Task-driven Teaching Method "Tax Accounting Practice". Finance and Economics (Academic Edition), (2017) No. 14.

[2] Chen Rong, et al. Application of Task-driven Teaching Method in Higher Vocational "Basic Accounting". Business Managers, (2017) No. 32

[3] Zheng Shuying, et al. Exploration and Practice of Project-Oriented Task-Driven Teaching Models: Taking Accounting Professional as an Example. Chinese and Foreign Exchange, (2017) No. 43.

[4] Su Li, et al. Application of the task-driven teaching method under the new situation in the "Financial Regulations and Accounting Professional Ethics" course. Chizi, (2017) No. 11.

[5] Xu Guannan, et al. The Application of Task-driven Teaching Method in the Course of "Financial Regulations and Accounting Professional Ethics". Global Market Information Review, (2017) No. 39, p. 66-67.

[6] Liu Yanqi, et al. Research on Budget Accounting Curriculum System Design Based on "Project Leading, Task Driven" Teaching Model. China Township Enterprise Accounting, (2017) No. 7, p. 228-229.

[7] Ren Xiaoling, et al. Project-oriented, task-driven reform of higher vocational accounting teaching model. Business Practice, (2017) No. 7. 